
TREATMENT \title{
TO BREAST
} CANCER

\author{
Yani Shivachev ${ }^{1}$, Stanislava Bogomilova ${ }^{1}$, Gergana Nenova ${ }^{2}$, Valentin Velchev ${ }^{3}$ \\ 1) Training sector of Kinesitherapy, Faculty of Public Health, Department of \\ Physiotherapy, rehabilitation, thalassotherapy, occupational diseases - Medical \\ University of Varna and University center of East medicine \\ 2) Training sector of Kinesitherapy, Faculty of Public Health, Medical Uni- \\ versity of Varna and Department of Orthopedics and Traumatology, University \\ Hospital for Active Treatment "St. Marina” Varna \\ 3) Department of Orthopedics and Traumatology, University Hospital for Active \\ Treatment "St. Marina” Varna, Bulgaria.
}

\begin{abstract}
Introduction: Worldwide breast cancer is the most common malignancy disease with a frequency of more than 6 million. The treatment consists of surgical intervention, chemotherapy, radiation, and often followup medical care in the long-term treatment is neglected. As a result of a partial or total mastectomy, one of the complications that patients develop is lymphedema, which may occur months or years after the surgery. This necessitates the search for systematic and effective approaches for these patients in order to improve physical and mental well-being, resocialization and return to previous levels of activity in daily life.

Case report: In 2019 a 58-year-old female patient, visited Medical University of Varna and University center of East medicine with the following complaints: pain in the armpit area, lymphedema of a right upper limb, a sense of weight and motor deficiency in the hand. In 2017 she is diagnosed with breast cancer by conducting an operative intervention consisting of a partial mastectomy with removal of 12 lymph nodes, followed by chemotherapy, radiotherapy treatment and medication therapy. For 2 years, the patient seeks help from a variety of healthcare professionals whose methods lead to short and unsatisfactory results. Impaired quality of life in daily activities is the main reason the patient to refer to the specialists at the University center of East medicine, offering a different and complex approach aimed at the patient's overall recovery.

Conclusion: Early diagnosis and subsequent successful treatment approach are the path to holistic, systematic and effective treatment in cancer patients.
\end{abstract}

Keywords: oncology rehabilitation, breast cancer, mastectomy, quality of life

\section{INTRODUCTION}

Breast cancer in women is the most common malignancy in the United States, accounting for about 250,000 cases a year [1]. After surgery, the symptoms observed are musculoskeletal pain, tingling, limited movement. Approximately $85 \%$ of patients experience complications such as lymphedema and axillary syndrome, leading to high levels of depression and social isolation [2]. This syndrome usually occurs between 5-8 weeks after surgery and is characterized by disorders of the subcutaneous tissues in the breast, arm, forearm and wrist. Most affect the motor function of the shoulder joint, causing pain and stiffness [3]. Along with this syndrome, lymphedema often occurs as a complication along the entire length of the upper limb on the affected side, the degree of which is determined by the operative approach and by how many lymph nodes are removed $[4,5]$. These clinical manifestations, combined with the side effects of chemotherapy and drug therapy, heighten the complaints of patients who need specialized physical and psychosocial care in the long term [6]. In some cases, recurrences also occur, which is the reason for the high mortality rate, and therefore systematic monitoring, rehabilitation and prevention measures are mandatory in the treatment and prevention of cancer patients.

\section{MATERIAL AND METHODS}

A 58-year-old female patient with many years of experience as a hairdresser appeals to the team of the University Center of Eastern Medicine at the Medical University of Varna with the following complaints: armpit pain, tingling of the fingers, lymphedema expressed throughout the upper extremity, feeling of heaviness in the arm and motor deficiency. In 2017, she is diagnosed with breast cancer and after post-operative surgery as a result of complaints she has stopped her work. By 2019, the patient is attempting different treatments that prove to be extremely unsatisfactory. The impaired quality of 
life in daily activities is the main reason for the patient to turn to specialists at the University Center of Eastern Medicine at the Medical University - Varna, where an analytical, combined kinesitherapy methodology was applied, consisting of:

- Treatment of trigger points in the upper limb, shoulder and back;

- Joint mobilization of the wrist, elbow and shoulder complex;

- $\quad$ Manual lymphatic drainage;

- $\quad$ Autostretching;

- Analytical gymnastics.

The kinesitherapy methodology was applied within one month, once a week for 30-60 minutes. As a result of the surgical resection of part of the axillary lymph nodes, soft tissue contractions and adhesions occur in the same area, and for this reason, the focus in the treatment of trigger points was on the pectoral muscles and those of the rotator cuff. The joint mobilizations we applied were mainly aimed at the shoulder complex, and we used the methods of manual lymphatic drainage to improve blood and lymph circulation. The patient was also given a complex of analytical exercises to perform at home.

The instruments we used to evaluate the degree of lymphedema and motor deficiency were centimetre and angleometry.

\section{RESULTS}

As a result of the kinesitherapy methodology we used, we reported changes after the first procedure. The patient reported a significant reduction in pain and tingling of the fingers, with the effect lasting about 48 hours. $\mathrm{n}$ the second procedure, the edema is visibly reduced, the patient feels the arm lighter and stronger. By the third procedure, the volume of movement in the shoulder joint was largely restored, the patient began to actively use the affected arm, and the quality of daily activities improved. The values that we received from centimeters and anglemetry before and after kinesitherapy are as follows:

Table 1. Centimeter data

\begin{tabular}{|c|c|c|c|}
\hline Values & Round wrist & Round forearm & Round arm \\
\hline 1 procedure before & $\begin{array}{c}\text { left }-20 \mathrm{~cm} \\
\text { right }-18 \mathrm{~cm}\end{array}$ & $\begin{array}{c}\text { left }-30 \mathrm{~cm} \\
\text { right }-27 \mathrm{~cm}\end{array}$ & $\begin{array}{c}\text { left }-33 \mathrm{~cm} \\
\text { right }-30 \mathrm{~cm}\end{array}$ \\
\hline 1 procedure after & left $-19 \mathrm{~cm}$ & left $-29 \mathrm{~cm}$ & left $-32 \mathrm{~cm}$ \\
\hline 2 procedure before & left $-19 \mathrm{~cm}$ & left $-29 \mathrm{~cm}$ & left $-32 \mathrm{~cm}$ \\
\hline 2 procedure after & left $-18 \mathrm{~cm}$ & left $-28 \mathrm{~cm}$ & left $-31 \mathrm{~cm}$ \\
\hline 3 procedure before & left $-18 \mathrm{~cm}$ & left $-28 \mathrm{~cm}$ & left $-31 \mathrm{~cm}$ \\
\hline 3 procedure after & left $-18 \mathrm{~cm}$ & left $-28 \mathrm{~cm}$ & \\
\hline
\end{tabular}

Table 2. Anglemetry data on shoulder joint

\begin{tabular}{|l|l|c|c|}
\hline Procedure & Values & Before & After \\
\hline 1 procedure & flexion & $150^{\circ}$ & $165^{\circ}$ \\
& abduction & $140^{\circ}$ & $70^{\circ}$ \\
& external rotation & $60^{\circ}$ & $62^{\circ}$ \\
\hline \multirow{2}{*}{2 procedure } & internal rotation & $55^{\circ}$ & $170^{\circ}$ \\
& flexion & $165^{\circ}$ & $155^{\circ}$ \\
& abduction & $150^{\circ}$ & $75^{\circ}$ \\
& external rotation & $70^{\circ}$ & $65^{\circ}$ \\
& internal rotation & $62^{\circ}$ & $175^{\circ}$ \\
& flexion & $170^{\circ}$ & $160^{\circ}$ \\
& abduction & $75^{\circ}$ & $80^{\circ}$ \\
& external rotation & $65^{\circ}$ & $70^{\circ}$ \\
\hline
\end{tabular}


Fig. 1. Percentage distribution of movements in the shoulder joint after treatment

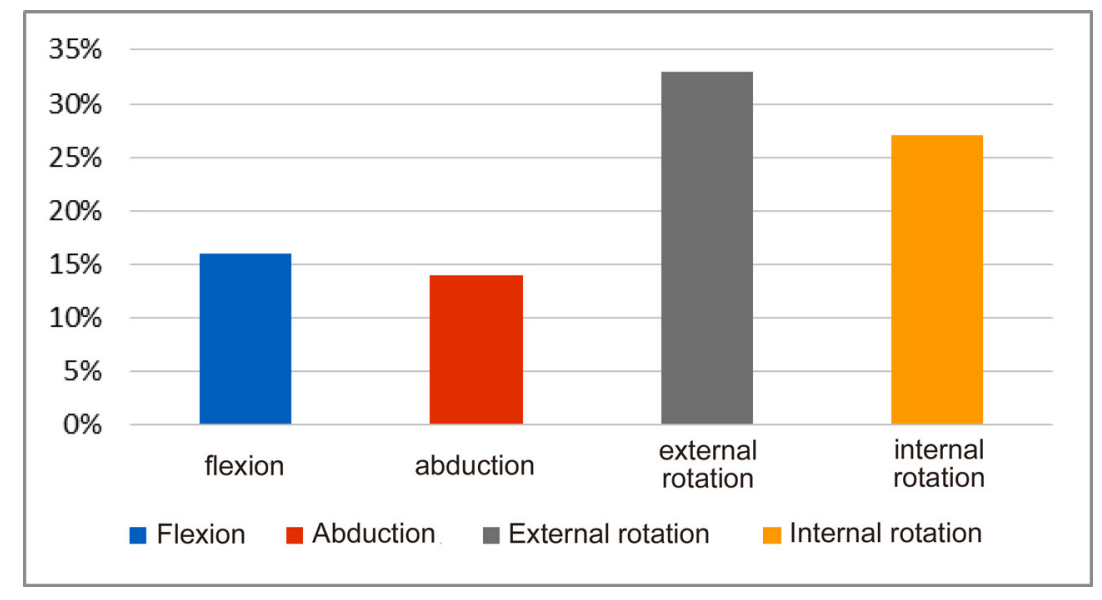

After the kinesitherapy methodology, there is an improvement in flexion (16\%), abduction (14\%), external rotation $(33 \%)$ and internal rotation $(27 \%)$. We can definitely consider that the proposed method leads to a significant impact on the range of movement in the shoulder joint.

\section{DISCUSSION}

Kinesitherapy in cancer patients is a mandatory component of overall treatment, regardless of the recovery phase. Lymphedema develops in women after mastectomy, one of the most common complications. Worldwide experience shows that most often rehabilitation care aimed at reducing lymphedema is manual and hardware lymphatic drainage, bandaging and drainage exercises [7, $8,9]$. Alone or in combination, these methods have their therapeutic effect in cancer patients with this complication, whose effect is short. The effects of lymphedema are associated not only with impaired blood and lymphatic circulation but also with local and reflex changes in the soft tissues and limited volume of movement. These changes lead to reduced work capacity and impaired quality of life. This daily fight against lymphedema and the accompanying symptoms such as pain, fatigue and depression necessitates a systematic and consistent approach in such patients $[10,11]$.

Some authors have indicated that selfadministration of manual lymphatic drainage does not sufficiently affect the reduction of lymphedema volume [12]. Contrary to this claim, literature sources claim that the combined effects of manual lymphatic drainage and therapeutic gymnastics have a positive curative and preventive effect $[13,14]$. This brings us to the search for a different approach, and for this reason, we have allowed ourselves to enrich current practices and offer an alternative in the treatment of patients with malignancies for a longer and more effective effect.

\section{CONCLUSION}

Lymphedema, as one of the most common complications after mastectomy, is a socially significant quality of life problem. Early diagnosis, patient awareness of the disease, follow-up therapeutic and preventative measures are essential in cancer patients. In this regard, a holistic kinesitherapy approach may be a successful alternative in the treatment of patients after mastectomy.

\section{REFERENCES:}

1. Badana ANS, Marino VR, Templeman ME, McMillan SC, Tofthagen CS, Small BJ, et al. Understanding the roles of patient symptoms and subjective appraisals in well-being among breast cancer patients. Support Care Cancer. 2019 Nov;27(11):42454252. [PubMed]

2. de Oliveira MMF, Gurgel MSC, Amorim BJ, Ramos CD, Derchain S, Furlan-Santos N, et al. Long term effects of manual lymphatic drainage and active exercises on physical morbidities, lymphoscintigraphy parameters and lymphedema formation in patients operated due to breast cancer: A clinical trial. PLoS One. 2018 Jan 5;13(1): e0189176. [PubMed]

3. Cho Y, Do J, Jung S, Kwon O, Jeon JY. Effects of a physical therapy program combined with manual lymphatic drainage on shoulder function, quality of life, lymphedema incidence, and pain in breast cancer patients with axillary web syndrome following axillary dissection. Support Care Cancer. 2016 May; 24(5):2047-2057. [PubMed]

4. Yen TW, Fan X, Sparapani R, Laud PW, Walker AP, NattingerAB. A contemporary, population-based study of lymphedemarisk factors in older women with breast cancer. Ann Surg Oncol. 2009 Apr;16(4):979-88. [PubMed]

5. Uzkeser H, Karatay S, Erdemci B, Koc M, Senel K. Efficacy of manual lymphatic drainage and intermittent pneumatic compression pump use in the treatment of lymphedema after mastectomy: a randomized controlled trial. Breast Cancer. 2015 May; 22(3):3007. [PubMed]

6. Cheng KKF, Wong WH, Koh C. Unmet needs mediate the relationship between symptoms and quality of life in breast cancer survivors. Support 
care cancer. 2016 May; 24(5):20252033. [PubMed]

7. Ko DS, Lerner R, Klose G, Cosimi AB. Effective treatment of lymphedema of the extremities. Arch Surg. 1998 Apr;133(4):452-8. [PubMed]

8. Golshan M, Smith B. Prevention and management of arm lymphedema in the patient with breast cancer. J Support Oncol. $2006 \mathrm{Sep}$;(8):381-6. [PubMed]

9. Zhang L, Fan A, Yan J, He Y, Zhang $\mathrm{H}$, Zhang $\mathrm{H}$, et al. Combining Manual Lymph Drainage with Physical Exercise after Modified Radical Mastectomy Effectively Prevents Upper Limb Lymphedema. Lymphat Res Biol.
2016 Jun;14(2):104-8. [PubMed]

10. Maass SW, Roorda C, Berendsen AJ, Verhaak PF, de Bock GH. The prevalence of long-term symptoms of depression and anxiety after breast cancer treatment: A systematic review. Maturitas. 2015 Sep; 82(1):100-8. [PubMed]

11. Spiegel D, Riba MB. Managing anxiety and depression during treatment. Breast J. 2015 Jan-Feb;21(1):97103. [PubMed]

12. Huang T-W, Tseng S-H, Lin CC, Bai C-H, Chen C-S, Hung C-S, et al. Effects of manual lymphatic drainage on breast cancer-related lymphedema: a systematic review and meta-analysis of randomized controlled trials. World $J$ Surg Oncol. 2013 Jan 24;11:15. [PubMed]

13. Devoogdt N, Geraerts I, Van Kampen M, De Vrieze T, Vos L, Neven P. Manual lymph drainage may not have a preventive effect on the development of breast cancer-related lymphoedema in the long term: a randomised trial. J Physiother. 2018 Oct; 64(4):245-254. [PubMed]

14. Mancheva P, Nenova G, Nedev N, Kraycheva E. [Role of rehabilitation in chronic disease.] Journal of medical college. 2018; 1:30-33. [in Bulgarian]

Please cite this article as: Shivachev Y, Bogomilova S, Nenova G, Velchev V. Oncology Rehabilitation - an alternative to breast cancer treatment. J of IMAB. 2020 Oct-Dec;26(4):3390-3393. DOI: https://doi.org/10.5272/jimab.2020264.3390

Received: 19/11/2019; Published online: 28/10/2020

Address for correspondence:

Yani Shivachev, Assist. Prof.

Department of Physiotherapy, rehabilitation, thalassotherapy, occupational diseases, Medical University of Varna and University centre of East medicine E-mail: qshivachevv@abv.bg 